\title{
How Cultural Models of Mind Affect Actor Director Task Performance
}

\author{
BY
}

\section{Andrew Frederick John Agnew}

\author{
A thesis \\ submitted to the Victoria University of Wellington \\ in fulfilment of the requirements of the degree of \\ Master of Sciences
}

Victoria University of Wellington 2021 


\title{
How Cultural Models of Mind Affect Actor Director Task Performance
}

\begin{abstract}
:
The actor director task (DT) has been used extensively to assess differences in perspective taking ability. Previous studies have found that individuals from collectivist cultures outperform those from individualist cultures in the DT. The current study uses an online form of the DT to assess individuals from European, New Zealand Pasifika and Māori cultural groups. Pasifika and Māori cultures tend to be categorised as collectivist, but have theory of mind norms that differ from previously assessed collectivist cultures. It is hypothesised that these norms will advantage Pasifika in the DT but not Māori. No significant differences are found in performance on the DT across all three cultural groups. All three groups replicated general performance on the DT in previous studies.
\end{abstract}




\section{Introduction}

Human communication frequently demands consideration of the perspective of another. Indeed, the ability to consider the mental state of another human is arguably fundamental to the fabric of society. It is therefore no surprise that the ability to consider the perspectives of others is a matter of intense study and debate in the field of psychology. This ability is what underpins theory of mind; the knowledge that others have minds and beliefs that are distinct from our own (Flavell et al., 1981; Hughes, 2002).

The early development of theory of mind has been assessed using tests of false belief. This is the understanding that others can hold beliefs about the world that are untrue. While theory of mind ultimately extends to reasoning about the motives, emotions and thoughts of others a necessary condition of theory of mind use is awareness that what we know can be distinct from the knowledge state of another. False belief understanding is the understanding that another can hold a belief about the world that is false. This understanding necessitates having knowledge that an actor does not and understanding that because they do not have that knowledge, their beliefs about the world are different from our own.

It was thought that an understanding of theory of mind developed around age four as this was when children began to show an explicit understanding of false belief in others (Perner et al., 1987). Later findings would challenge this conclusion as younger children demonstrated an implicit understanding of false belief in anticipatory looking (Clements \& Perner, 1994; Rubio-Fernández \& Geurts, 2013; Southgate et al., 2007) and looking time (Onishi \& Baillargeon, 2005; Surian et al., 2007; Träuble et al., 2010). The significance of these findings remains hotly debated with a number of theoretical explanations (Apperly \& Butterfill, 2009; Baillargeon et al., 2010; Low, 2010; Perner \& Ruffman, 2005; Ruffman et 
al., 2001, 2012; Schneider et al., 2014). Debate over the significance of implicit understanding prompted the extension of tasks across cultures (Sabbagh et al., 2006). It was found that there was no variation across cultures in performance on implicit tasks or explicit performance prior to age four.

This lack of cross cultural variation has led to the conclusion that an understanding of false belief and therefore the ability to reason about the perspectives of others is not influenced by culture (Wu \& Keysar, 2007). However, assessment of the performance of children on explicit assessments of false belief and perspective taking after age four has revealed variation across cultures (Liu et al., 2008). These differences appear to represent differences in perspective taking that extend into adulthood (Wu \& Keysar, 2007; Barrett et al., 2013). This suggests that the ability to reason about perspectives of others is early developing and influenced little by culture but the use of that ability is shaped by culture. Examining variations in perspective taking ability across cultures therefore better informs us of how different cultures actively reason about the perspectives of others. The focus of this study is on how perspective taking ability varies across three cultural groups with varying norms surrounding the minds of others. I aim to better understand how beliefs about the mind have influenced the use of perspective taking.

\subsection{What Might Account for Differences?}

Theoretical explanations for differences in perspective taking across cultures vary. Early theoretical explanation has focused on the differences in self-construal between Western societies and a number of Asian societies (Markus \& Kitayama, 1991). It was argued that Western society placed a greater emphasis on the self as independent. As such, judgements about oneself and others would focus on individual traits and immediate motives. In contrast, it was held that Asian societies tended to emphasise an interdependence of self, 
meaning that judgements focused on one's role in relation to others. This notion has been supported by a range of findings in which Japanese, Indian and Chinese participants tended to favour situational and role based explanations for the actions of others where US participants tended to favour dispositional explanations (Hamilton et al., 1983; Miller, 1984; Choi et al., 1999; Ji et al., 2000; Masuda \& Nisbett, 2001; Nisbett \& Miyamoto, 2005).

This difference in self-construal was linked to two cultural groupings: individualist and collectivist. These categorisations were originally proposed by Hofstede in 1984. Western society was presented as individualist; placing emphasis on an individual's choices and preferences in their social values. In contrast, Eastern societies were presented as collectivist; emphasising social harmony and interpersonal relatedness in their social values.

Though this distinction has been referenced often in explaining cross cultural findings (Chopik et al., 2017; Kessler et al., 2014; Ma-Kellams \& Blascovich, 2012; Markus \& Kitayama, 1991; Wong \& Wyer, 2016), it has been argued that the use of a wide ranging categorisation of cultures has limited the scope of cross cultural study and ignored nuance in how different cultures approach perspective taking (Bond, 2002; Brewer \& Chen, 2007). Evidence of this nuance can be found in assessments of cultural groups that have had relatively little attention paid to them in assessments of perspective taking. In a comparison of the judgements of eight small-scale societies to larger-scale industrialised societies it was found that outcome tended to be weighted more heavily than intention in judgements of an individual's actions (Barrett et al., 2016). These societies tended to emphasise communal harmony, favouring an interdependent concept of self and therefore would tend to represent more "collectivist" societies. Despite this, there is variation in the degree to which situational factors are emphasised in judgments. Among those eight societies were Pacific Island communities in rural Fiji (indigenous iTaukei Fijians) who were further examined by 
McNamara et al. in 2019. iTaukei Fijians, Indo-Fijian and North American judgements of accidents and failed attempts at completing an act were compared. It was found that iTaukei Fijians judged accidents more harshly than the other two cultural groups. However, when prompted to consider the thoughts of an actor, iTaukei judgements of failed intentional attempts shifted to be harsher than unintentional bad outcomes in accidents. This finding suggests that variations in perspective taking are not a consequence of variations in the capacity to perspective take but in how it is exercised. It also supports the notion that responses to perspective taking tasks are influenced by the conditions under which the task is presented. While the collectivist/individualist divide is a useful one, if we are to understand how perspective taking is influenced by cultures we should examine other ways that different cultures think about the minds of others; the variations in cultural concepts of theory of mind.

In a 2011 anthropological conference discussing theory of mind across cultures as many as six distinct forms of theory of mind were identified. Differing concepts of the form the mind itself takes would likely have a significant effect on performance on tasks involving perspective taking. For example; the native Mayans of Mexico normatively hold that the mind is opaque (Luhrmann 2011). This means that consideration of the thoughts of others is not typical in judgements of desire and action. Explicit communication of one's mental state is thought to be the sole clear communication of intent. This opacity doctrine is also present in a number of pacific communities (Rumsey, 2008) including the Pasifika referenced earlier.

Distinctions in cultural norms are not the only noteworthy manner in which culture might affect conceptualisation of other minds. Tactile inputs like pain are important in empathic engagement for healers on the island of Yap (Throop, 2012), suggesting that some cultures might have distinct modes of engaging with the perspectives of others. Language 
also appears to play a significant role in perspective taking development. Adult speakers of a Nicaraguan sign language improved performance on a perspective taking task as they acquired expressions associated with the perspectives of others (Pyers \& Senghas, 2009). Assumptions about what is referred to in communicative expressions also appears to vary across cultures (Li et al., 2018).

While it is important to note that explanatory constructs such as the collectivist/individualist divide are useful, it is clear that the manner in which culture shapes perspective taking is rich in nuance extending to specific and varied norms and language use.

\subsection{The Actor Director Task}

Among the assessments previously used to examine differences in perspective taking ability is the actor director task. This task was first utilised by Wu and Keysar in 2007 and involved a director giving a participant instructions to move an object about a grid. Some of these instructions were unambiguous, but others could ambiguously refer to objects hidden from the director but known to the participant. Participant response times and mistakes were examined on ambiguous instructions as compared to unambiguous. The task, in theory, assesses the participant's ability to act on the state of another's knowledge. Performance of US adults was compared to Chinese adults. It was found that Chinese adults made fewer mistakes and responded more quickly to ambiguous prompts. The authors suggested this was because US participants had an egocentric bias; they struggled to separate their own perspective from given instructions. This bias was thought to be absent in the collectivist Chinese participants.

This finding was replicated and expanded by Luk et al. in 2012. Hong Kong bilingual speakers of English and Cantonese-Chinese were assessed. They were primed with US or Chinese cultural images before carrying out the actor director task and all instructions 
were given in Cantonese-Chinese. It was found that those primed with US imagery made more mistakes and had slower reaction times than those primed with Chinese cultural imagery. This finding is particularly noteworthy in that cultural priming appears to be the sole determinant of performance difference. These findings have been used to argue that the actor director task assess an individual's ability to infer and act on the perspective of another rather than a more general ability to follow rules (Legg et al., 2017, Wu \& Keysar, 2007).

However, much like early findings of differences in judgements of others across cultures, the actor director task has thus far been limited to comparisons between the Western US and Asian China. This paper expands use of the actor director task to Pasifika much as was done by McNamara et al. (2019) in moral judgements as well as to Māori, a group untested at time of writing. The original study was to include Indo-Fijians in order to compare the performance of a collectivist society that does not subscribe to opacity of mind norms to iTaukei Fijians. However, unanticipated constraints placed on this study by the COVID-19 outbreak made collecting data on this cultural groups in Fiji untenable. Instead, resources were allocated to examining Māori and New Zealand Pasifika as a cultural groups related to the original target populations and previously unexplored with the actor-director paradigm. Additionally, an online version of the paradigm was necessary to use in testing. This form of the director task has become popular in social cognition research (Apperly et al., 2010; Dumontheil, Apperly, et al., 2010; Dumontheil, Küster, et al., 2010; Legg et al., n.d.; RubioFernández, 2017) with results comparable to those of in person uses of the paradigm.

New Zealand Pasifika as a cultural group includes individuals of: Samoan, Cook Island, Tongan, Fijian, Tokelauan, Niuean and Tubaluan descent (Teaiwa \& Mallon, 2005). It is a broad group that first entered common parlance in New Zealand as blanket term perpetuated by the New Zealand media from the 1950s to 1980s (Macpherson 1996). Identifica- 
tion as New Zealand Pasifika does not represent a subscription to a monolithic cultural identity so much as a kinship with other peoples of Pacific descent. This kinship is expressed in shared colonial experiences, interconnection of traditional practices and a more modern sharing of socioeconomic struggles (Teaiwa \& Mallon, 2005). Pasifika communities in New Zealand tend to maintain values that emphasises interdependent social practice (Ka\&amp et al., 2005; Mavoa et al., 2003; Ochs, 1982) in child rearing. Such communities also score highly on collectivist measures (Podsiadlowski \& Fox, 2011) and express values associated with collectivism (Tamasese et al. 2005; Brison, 2001; Gervais, 2013; Kline et al., 2013). While New Zealand Pasifika are not immersed in the same environment and social context as the original target population (iTaukei Fijians) Pacific peoples do tend to subscribe to the mental opacity doctrine in perspective taking (Rumsey, 2008) which is distinct from the norms of previously assessed cultures (Markus \& Kitayama, 1991).

Māori peoples are thought to have descended from settlers from Society and Cook Islands (Davidson 1980; Anderson 2014). As a cultural group Māori tend to score higher on collectivist measures than New Zealand Europeans (Shulruf et al., 2007) and express collectivist cultural orientation (Durie 1995). In addition to this, Māori students tend to regard the self as interdependent (Harrington \& Liu, 2002). Despite this, and like New Zealand Pasifika, Māori cultural norms surrounding the mind are distinct from those of other collectivist cultures. The concept of "wairua" is an important part of Māori conceptualisation of the self and the mind (Kennedy et al., 2015). The term is often simply translated as the "spiritual world" or the "soul” (Valentine \& Tassell, 2017). Māori Marsden, as related by Royal (2003), described wairua as the spiritual universe that pervades all things. It can be felt by individuals and has a component unique to each living entity (Bidois 2016). Modern investigations into how contemporary Māori peoples define and understand wairua have found no 
consistent definition (Gall et al., 2011). However, themes of wairua being: fundamental, without boundaries, a perceived sensation and interpersonal in nature have been identified amongst contemporary Māori peoples (Valentine et al., 2017). Wairua is bound to the body and given form by "mauri", an essential force common to all living things (Barlow, 1991; Mead, 2003; Moon, 2005). Mauri is not felt directly but is thought to have an effect on an individual and their environment. Moon (2005) relates Hohepa Kereopa's description of mauri as an interdependent force; members of a community living in a home can make it come alive with mauri by conceptualising the space as a home. Kereopa expands on forms of mauri present in interpersonal interactions by offering the example of expressing hate for another person. Your own feelings, and the reaction of that person, creates a form of mauri that affects both parties. Resolution of the emotional root of the expression is essential for resolving the created mauri which might otherwise adversely affect a person. This concept of the self and the world not only emphasises social interdependence but also an attendance to the emotional and spiritual significance of deeds (Pohatu, 2011). Where the Western individualist theory of mind tends to be secular in nature (Luhrmann, 2011) the Māori theory of mind has a strong spiritual element that is felt and expressed emotionally (Kennedy et al., 2015).

European New Zealanders tend to mirror Western norms in self concept and individualism (Fagenson-Eland et al., 2004; Kemmelmeier et al., 2003). In contrast to this, New Zealand Pasifika emphasise collectivism and opacity of mind norms while Māori emphasise collectivism and a distinctly spiritual approach to theory of mind. Thus, I explore how culture affects performance on the actor director task when cultures differ on perspective taking norms as well as collectivist/individualist emphasis. It is hypothesised that there will be a significant difference between European New Zealander, Māori and Pasifika performance. 
Whether a subscription to mental opacity will affect Pasifika performance is unclear. McNamara et al. (2019) found that iTaukei Fijians tend to place the emphasis of consideration on the situation being assessed rather than an actor's mental state. However, these iTaukei participants were not blind to mental state. Given that performance on the actor director task demands attendance to a situational state, it is hypothesised that Pasifika will outperform Westerners in the actor director task. Māori culture tends to be collectivist (Shulruf et al., 2007) and collectivist cultures have previously outperformed individualist cultures in the actor director task (Luk et al., 2012). The effect of the spiritual elements of Māori theory of mind norms is unclear though the task involves a director that isn't likely to be emotionally or spiritually significant to the participant. On the basis of Māori culture tending to be collectivist alone I hypothesise that Māori will outperform Europeans but there will be no significant difference in performance between Māori and Pasifika. It is hypothesised that all cultural groups will make fewer errors when a distractor object is absent.

\section{Method}

\subsection{Participants}

100 Pasifika, 101 Māori and 102 Pakeha/European participants were recruited online over a period of five weeks. Table 1 below describes participants.

\begin{tabular}{ccc}
\hline & Participants N & $\begin{array}{c}\text { Age } \\
\text { Mean (Min-Max) }\end{array}$ \\
\hline Pasifika & 100 & $36(18-72)$ \\
Māori & 101 & $50(20-87)$ \\
Pakeha/European & 102 & $42(19-78)$ \\
Total & 303 & $43(18-87)$ \\
\hline
\end{tabular}

Table 1: Participant numbers and age by ethnicity. 


\subsection{Materials}

Computer generated images of $4 \times 4$ grids of shelves with five of the shelves of the grid occluded such that objects on those shelves are visible only on one side, hereafter referred to as the actor side. A cartoon director (see figure 1) was visible on the other side of the shelves and gave instructions with a speech bubble. Sixteen images of objects total were used in testing; eight trios of objects with unambiguous uses and forms. The trios were: balls, blocks, shirts, mugs, keys, stars, socks and hearts. Each trio was be the same colour but varied in size.

Thirty-two unique arrays were generated for the task. Each array presents eight or seven objects depending on whether a competitor object is present or absent. If a competitor object is to be present then all three sizes of an object trio were present. If a competitor object is to be absent then only two objects from an object trio were present. The remaining five objects are individual instances of the other object trios. No two of the remaining five objects were from the same object category and all were be of the intermediate size. Eight of the arrays had the largest object in the presented trio on an occluded shelf and the other two mutually visible. Eight of the arrays had the smallest object in the presented trio on an occluded shelf and the other two mutually visible.

These arrays are hereafter referred to as the ambiguous arrays. The remaining sixteen arrays were identical to the ambiguous arrays except that the largest or smallest object respectively was absent. These arrays are hereafter referred to as unambiguous arrays. This produced sixteen pairs of ambiguous and unambiguous arrays (see figure 1 for an example of a matched pair of arrays). One familiarisation array will be created with a ball object trio. The largest ball will be on an occluded shelf. 

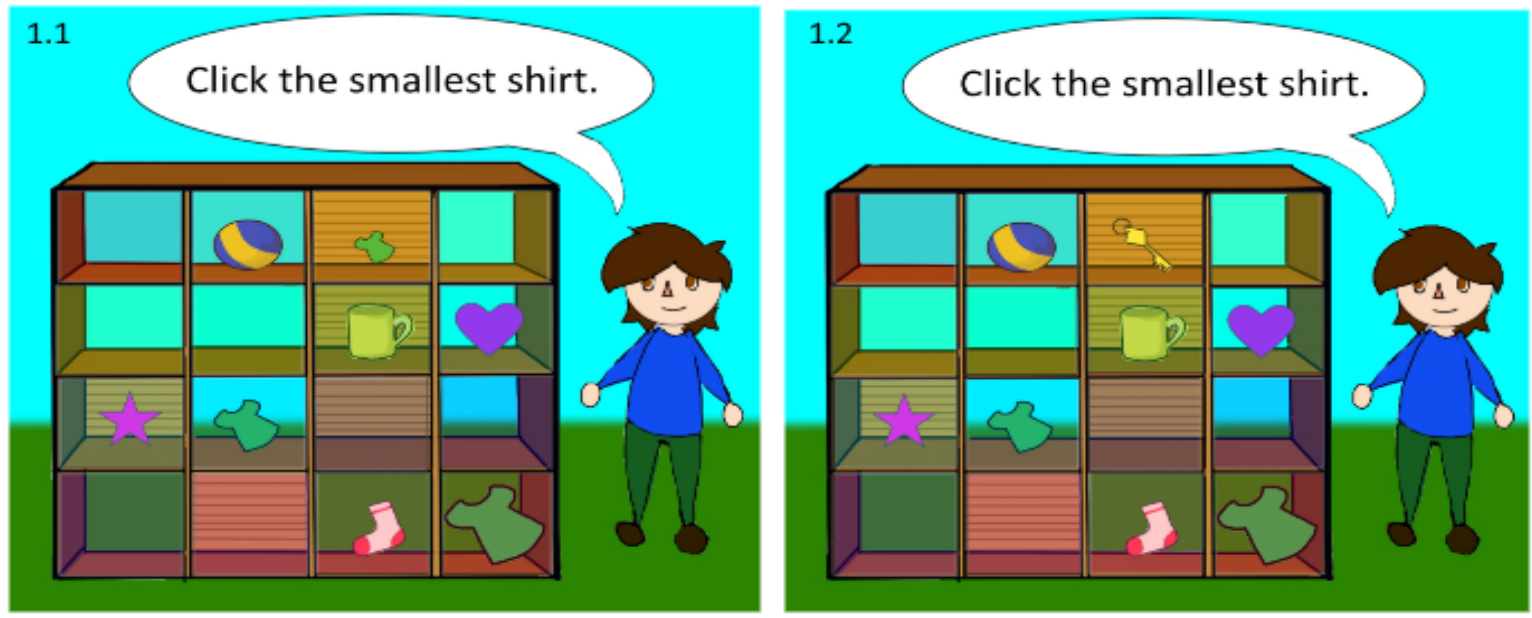

Figure 1: Matched pair of arrays. 1.1 contains a distractor object (the smallest shirt) while in 1.2 the object is replaced with a key.

\subsection{Procedure}

Participants were given text based instructions. The instructions and other materials used in this experiment are available on the OSF page for this experiment, linked in the appendix. All participants received instructions in English. Participants were told that they will be playing a cooperation game with an imaginary partner. They are to follow their partner's instructions as quickly and accurately as possible. Participants were then presented with the familiarisation array. The partner was introduced with a text box. The familiarisation array was then presented from the partner's perspective and a text box informed the participant that: "This is how the shelves look to your partner. They cannot see objects behind the screens." The participant's "perspective" is then restored and the director gave them three instructions via speech bubble. Each instruction followed the general form of: "click on the $\mathrm{x}$ " where " $\mathrm{x}$ " is an object that is mutually visible on the array. Each instruction remained on screen until an object was clicked on and "continue" was selected. The first instruction was "click on the smallest ball". 
Given that the smallest ball was occluded, the correct response was to select the medium sized ball. Once continue was clicked on a textbox with "correct" or "incorrect" appeared followed by: "your partner could only see the medium and large sized balls, so they meant the medium sized ball, even though you could see an even smaller one. "The next two familiarisation instructions were unambiguous with only "correct" and "incorrect" as feedback. After the familiarisation trial the participant was informed that they were about to begin the game proper. They were reminded that the director cannot see objects behind the shelves and that if their partner asked for an object of a specific size, they meant the one they could see, even if a larger or smaller object was on the shelves. This reminder, and the explicit feedback on the ambiguous familiarisation trial were not in the original form of this paradigm (Legg et al., 2017). They were included because over half of the participants recruited in the trial run of this task were failing to meet criteria for analysis. This appeared to be due to confusion about the intention of the director in ambiguous trials, suggesting that for many participants it was not intuitive that the digital director had a limited perspective.

Following familiarisation, each of the 32 arrays were presented in a semirandomised order such that matched ambiguous and unambiguous arrays were presented sixteen arrays apart. The order arrays were presented was reversed for half of the participants. Each array was presented with three instructions. Two instructions were unambiguous "filler" instructions referring to one of the mutually visible non-trio objects. One instruction was the test instruction and referred to the largest or smallest object in a presented trio. If the array was part of a pairing with the largest object on an occluded shelf in the ambiguous array, then the instruction referred to the largest object. If the ambiguous array in the pairing had the smallest object on an occluded shelf then the instruction referred to the smallest object. Instruction order for each array was randomised. 
The manipulated variable within subjects was the presence of a distractor object on an occluded shelf on test instructions; during experimental trials the object was present and during control trials it was absent. The dependant variable is reported as error rate, in line with previous uses of this paradigm (Legg et al., 2017). Error rate is calculated based on the number of incorrect selections over the total trials of distractor conditions.

Participants were then administered a comprehension check (see below) and asked to describe any methods they used to pass the task in a textbox. After this

\subsection{Comprehension Check}

After the arrays were presented the participant completed a comprehension check. They were presented with an array with the numbers 1 to 16 on each shelf. They were asked to click on the numbers the partner cannot see. They were then asked if they understood that the director's perspective differed from their own. Both of these checks were put in place to make certain that participants understood that the director's perspective was distinct from their own. Any participants that made mistakes in the task or answered "no" to the question were excluded from final analysis.

Of the 303 participants, 83 failed to pass the comprehension check. To assess the efficacy of the manipulation check a two-way 2 (distractor: present or absent) x 2 (criteria: met or unmet) within subjects ANOVA with repeated measures on the distractor variable was performed on error rates. There was a significant main effect of criteria $F(1,301)=$ 199.307, $p<.001$ and a significant interaction between criteria and distractor $F(1,301)=$ $189.979, p<.001$. The mean error rates in trials without a distractor were similar regardless of whether the criteria was met $1.6 \%$, CI.95[0.2\%,2.9\%] or unmet $2.7 \%$, CI95[0.7\%,4.8\%]. The mean error rates in trials with a distractor were very distinct with an error rate of $71.1 \%$, 
CI95[62.8\%,79.3\%] amongst those that did not meet criteria and an error rate of $12.5 \%$, $\mathrm{CI}[6.8 \%, 18.2 \%]$ amongst those that did.

This would suggest that those that failed to meet inclusion criteria were paying attention as they performed just as well as those that met criteria on control trials. The mean error rate of $71.1 \%$ suggests that they did not understand that they were to respond to distractor questions from the director's perspective. It was therefore concluded that the comprehension check was effective in identifying those that did not understand the task.

\subsection{Psychometrics}

Several psychometrics were included after the final comprehension check in an effort to better understand what might be influencing differences in performance on the director task.

Cook-Medley Hostility Scale:

This is a self-report measure of interpersonal hostility (Barefoot at al., 1989) used to index distrust and hostility towards others. This study uses a 19-point short form of the scale in order to act as a covariate to understand how temperamental differences in interpersonal relations might affect performances on the task. Participants are given the prompt: "Please indicate whether you think each of the following statements is True or False." Participants will then rate statements on a 7-point likert scale ranging from 1 (definitely false) to 7 (definitely true).

Empathy Quotient (Short Form):

The EQ is a self-report measure of empathic ability (Baron-Cohen \& Wheelwright, 2004) used to index recognition of the emotional state of another and the experience of situation appropriate emotion in response to that state. This study uses a 22-point short form of the scale in order to act as a covariate to understand how emotional recognition (thought to play a role in theory of mind) might be associated with task performance. Participants are given the prompt: "please indicate how much you agree or disagree that each statement ap16 
plies to you." Participants will then rate statements on a 7-point likert scale ranging from 1 (strongly disagree) to 7 (strongly agree).

Interpersonal Reactivity Index (Perspective Taking Ability Questions):

The IRI is a self-report measure of four aspects of empathy (Davidson, 1980). This task uses only questions that index perspective taking ability as the other three dimensions of empathy examined are better covered by the EQ or not relevant to theory of mind. Participant performance will act as a covariate to examine how perspective taking ability is associated with task performance. Participants are given the prompt: "please indicate how much you agree or disagree that each statement below describes you." Participants will then rate statements on a 7-point likert scale ranging from 1 (strongly disagree) to 7 (strongly agree).

\section{Results}

I began with a two-way 2 (distractor: present or absent) x 3 (ethnicity: Pasifika, Māori or Pakeha/European) mixed ANOVA with repeated measures on the distractor variable. There was a significant main effect of distractor $F(1,217)=25.186, p<.001$ but the main effect of ethnicity was not significant $F(2,217)=189, p=.828$. Error rates of ethnicities across distractors are presented below in table 2 .

\begin{tabular}{ccc}
\hline Culture & $\begin{array}{c}\text { Distractor Present Error Rate } \\
\text { Mean }[95 \% \mathrm{CI}]\end{array}$ & $\begin{array}{c}\text { Distractor Absent Error Rate } \\
\text { Mean }[95 \% \mathrm{CI}]\end{array}$ \\
\hline Pasifika & $9.4[3,15.9]$ & $2.6[.9,4.2]$ \\
Māori & $10.1[3.7,16.5]$ & $1.3[-.3,2.9]$ \\
Pakeha/European & $13[6.8,19.2]$ & $1.2[-.4,2.8]$ \\
Overall & $10.8[7.2,14.5]$ & $1.7[.8,2.6]$ \\
\hline
\end{tabular}

Table 2: Error rates across distractor conditions by culture. 
Error rates were $10.8 \%$ when a distractor was present across all ethnicities as compared to $1.7 \%$ when the distractor was absent; a significant difference. This supports the hypothesis that all groups would have greater error rates when the distractor was present, and is in line with previous uses of the paradigm. However, the hypotheses that Pasifika and Māori would outperform Pakeha/Europeans was not supported as there was no significant difference in error rates across ethnicities. While the use of a mixed ANOVA does mean that confidence intervals reached impossible values, a follow up analysis using the Kruskal Wallis test found no effect of ethnicity when the distractor was present $\chi 2(2)=.176, p=.916$ or absent $\chi 2(2)=1.166, p=.558$.

\subsection{Psychometric Analysis}

In order to examine the relationship between psychometric scores included in the experiment and performance on the task I performed several multiple linear regression calculations. For each ethnicity a multiple linear regression was calculated to predict error rate based on their IRI, EQ and Cook-Medley Hostility Scale scores. Participants that failed the comprehension checks were excluded from analysis. Across all ethnicities no factor was a significant predictor of error rate (all $\mathrm{P}$ values $>.1$ ). Beta values are reported in table 3 below.

\begin{tabular}{lccc}
\hline Culture & IRI Beta $[95 \% \mathrm{CI}]$ & EQ Beta $[95 \% \mathrm{CI}]$ & CMHost Beta $[95 \% \mathrm{CI}]$ \\
\hline Pasifika & $.002[.007,-.003]$ & $.002[.005,-.001]$ & $.000[.002,-.002]$ \\
Māori & $-.009[-.003,-.015]$ & $.002[.006,-.002]$ & $-.002[0,-.004]$ \\
Pakeha/European & $.004[.011,-.003]$ & $-.005[-.001,-.009]$ & $.001[.003,-.001]$ \\
\hline \multicolumn{2}{c}{ Table 3: Psychometric B values across cultures as a predictor of error rate on test trials. All P values $>.1}$.
\end{tabular}


In order to examine the relationship between psychometric scores and the meeting of inclusion criteria I performed several more multiple linear regression calculations. For each ethnicity a multiple linear regression was calculated to predict whether they would meet inclusion criteria based on their IRI, EQ and Cook-Medley Hostility scale scores. I included this analysis because almost a third ( 83 of 303 ) participants failed to meet inclusion criteria. Those participants that failed to meet my inclusion criteria did seem to be paying attention as they performed just as well as those that met my criteria did on control trials. It was only on test trials that those that did not meet inclusion criteria differed from those that did in that they had far greater rates error. This would suggest it was a lack of understanding of the task, rather than attendance, that caused the participant to fail to meet inclusion criteria.

The Beta values of each calculation are reported in table 4 below. A lower score on the Cook Medley Hostility scale was significantly predictive of meeting inclusion criteria for Pasifika and Pakeha $(\mathrm{P}<.05)$ but not Māori. A higher score on the EQ short was significantly predictive of meeting inclusion criteria for Māori $(\mathrm{P}<.005)$ but not Pakeha or Pasifika. It is noteworthy that the EQ Short approached predictive significance for Pasifika ( $\mathrm{P}<$ .1) but not Pakeha $(\mathrm{P}>.5)$. No other factors were predictors of meeting criteria $(\mathrm{P}>.5)$.

\begin{tabular}{llll}
\hline Culture & IRI Beta $[95 \% \mathrm{CI}]$ & EQ Beta $[95 \% \mathrm{CI}]$ & CMHost Beta $[95 \% \mathrm{CI}]$ \\
\hline Pasifika & $.004[.011,-.003]$ & $.008[.013, .003]$ & $-.007[-.004,-.01]^{*}$ \\
Māori & $-.014[-.005,-.023]$ & $.018[.023, .013]^{*}$ & $.001[.004,-.002]$ \\
Pakeha/European & $.009[.017, .001]$ & $.003[.007,-.001]$ & $-.005[-.002,-.007]^{*}$ \\
\hline
\end{tabular}
significant $(P<.05)$. 


\section{Discussion}

My findings replicate those of previous uses of the actor director task in that the presence of a distractor object resulted in a greater error rate across cultural groups. However, the differences in performance between cultural groups was slight and did not achieve significance. Thus, the hypotheses that Pasifika and Māori would outperform Pakeha was not supported. There are a number of possible explanations for this finding. The first is that the form of perspective taking ability indexed by this task does not vary across the ethnicities examined. This explanation would challenge the assertion made by $\mathrm{Wu}$ and Keysar (2007) that collectivist societies outperform individualists in the director task. It remains possible that the advantages enjoyed by collectivist societies in the director task are being suppressed in Pasifika and Māori by their distinct theory of mind norms (Rumsey, 2008). However, if this is the case, then at a minimum the collectivist/individualist divide is an inadequate construct for explaining performance differences across cultural groups as several authors have argued (Bond, 2002; Brewer \& Chen, 2007). Amongst Pasifika a subscription to opacity of mind may have meant that the director's ignorance of occluded objects was not intuitively assumed, despite early instructions. The participants may instead have focused on the directive without assuming a different knowledge state in the director and therefore have made more errors in responding. It should be noted that this does not represent any inability to attend to the perspectives of others so much as an attendance to the strict factual details of an utterance over assuming knowledge states. Amongst Māori participants the fact that the task was without obvious emotional or natural human expression may have meant that the intent of the director was not as intuitive to them as it might have been to Chinese participants in the original study. 
Another possible explanation is that the task in this form does not adequately capture fine differences in performance. The mean error rate of Pakeha was lower than both the Māori and Pasifika groups and it may be that fine differences in performance were not captured. There are a number of limitations inherent to the method I used that may have resulted in this. First, the director task was in an online format rather than the more intuitive inperson forms of the task (Luk et al., 2012; Wu \& Keysar, 2007). The director task performed in person uses a confederate posing as another participant and frames the task as collaboration between two subjects rather than a fabricated director.

While previous online uses of the director task have had comparable results to those using in person methods (Legg et al., 2017; Rubio-Fernández, 2017), the subjects in such studies were university students of Western institutions or participants curated for online testing. These populations are likely to be familiar with the workings of computerised psychology experiments. All participants in the current study were recruited online and, regardless of cultural group, are unlikely to have experience with computerised psychology experiments. In support of this is the fact that well over half of the participants in the pilot form of this study failed to pass the comprehension check at the conclusion of the director task.

The pilot form of the study was based directly on Legg et al's (2007) computerised form of the director task. Instructions in that task were not explicit in communicating that objects behind screens could not be seen by the director. I adjusted the familiarisation section of the task to communicate this explicitly to participants, as well as that the director was issuing instructions based on their perspective. Even with more explicit instructions, 83 of 303 participants failed to pass the comprehension check. In contrast to this, all thirty of the participants recruited for the same director task in Legg at al's (2007) study passed the same comprehension check. It may be that repeating the experiment under the original in-person 
conditions would be more intuitive to participants from the cultural backgrounds tested and therefore finer differences in performance may be identifiable.

Another limitation that an online platform introduced was error tracking. In the inperson forms of the task participant selections are marked based on the object they reach for and touch, but it is noted that they would often recognise their mistake and correct themselves shortly thereafter (Luk et al., 2012; Wu \& Keysar, 2007). Such mistakes were, nonetheless, marked as errors. The online form of the task allows for participants to change their selection and imposes no obvious time limit. This is due to a limitation of the online platform and does not seem to have resulted in an absence of distractor effect. However, it may have resulted in less sensitivity to small performance differences across cultural groups.

It is also important to note that none of the psychometric measures were predictive of performance on the task. The EQ short and Cook-Medley Hostility scale both index aspects of perspective tracking that should not have been relevant to the task itself. The EQ short indexes recognition of emotion in others while the Cook-Medley Hostility scale indexes interpersonal distrust. The director task does not vary in emotional valence so it is not surprising to find that these measures were not predictive of performance. However, the section of the IRI used pertained specifically to perspective taking ability. It is therefore surprising that performance on this measure was not predictive of performance on the actor director task.

One possible explanation for this is tied to previous critiques of tasks that challenge perspective taking ability; that such tasks also tax the more general ability of executive control (Kuhlen \& Brennan, 2010; Qureshi et al., 2010). This is because the director task demands that an alternate perspective be represented and separated from one's own perspective. Differences in the development of executive control have been found across cultures 
(Wellman et al., 2001) and it is plausible that performance differences on this task are bound to this more general ability. This limitation has previously been explored with a body of participants drawn from a Western university (Rubio-Fernández, 2017) and it has been found that in a modified director task, participants did actively represent the perspective state of the director. Were such a finding to be replicated with Māori and Pasifika participants, this issue could be addressed.

It is also noteworthy that Cook Medley Hostility scale and EQ short were variously predictive of participants meeting inclusion criteria. Their predictive power was very small, but nonetheless significant. Lower scores on the Cook Medley Hostility scale were predictive of meeting inclusion criteria for Pakeha and Pasifika but not Maori. This is an index of interpersonal hostility and the tendency to view another with distrust. Therefore, a participant was more likely to meet inclusion criteria if they were more trusting less interpersonally hostile but only if they were Pakeha or Pasifika. Higher scores on the EQ short were predictive of meeting inclusion criteria for Maori participants only. This index is of an individual's tendency to empathise with the emotional state of others. Therefore, Maori participants that tended to empathise more also tended to meet inclusion criteria.

Inclusion criteria was an assessment of the participant's comprehension that what the director could see was distinct from their own perspective. This is an emotionally neutral task and participants that made errors in this task also responded to the majority of test trials incorrectly. This suggests that participants that didn't meet inclusion criteria did not understand the task. I have already discussed how the online director task may not have been intuitive for my participants. It may therefore follow that Pakeha and Pasifika participants that favour a trusting approach to others also tended to make few assumptions about the intention of the director and attended more to the intention behind their instructions rather than 
what they immediately intuitied, despite differences in underlying theory of mind subscriptions. As previously discussed, Maori may have found the task unintuitive because the online and cartoon state of the director is without clear meaningful emotional valence which is normatively significant in Maori interpersonal interaction (Valentine et al., 2017) . This may be why a higher score on the EQ short was predictive of Maori meeting inclusion specifically; those participants that more readily empathised with others more readily treated the cartoon director and their intentions as emotionally important. This in turn may have eased comprehension of the director's instructions.

Much of this discussion has focused on the limitations of an online form of the director task. Despite significant differences in normative theory of mind subscriptions (Rumsey, 2008) and performance on other perspective taking tasks (Barrett et al., 2016; McNamara et al., 2019) it appears that Pasifika and Māori performance on the director task did not differ from that of Pakeha. It remains unclear whether this is a limitation of a task format that is not immediately intuitive to tested populations. Previous testing has used in person methods with efforts made to ensure testing is intuitive and naturalistic.

The most obvious future direction of director task testing is use of the in person form of the task. This would rule out many of the limitations discussed here. The reverse of this logic also applies to assessment of limitations: replicating the original findings of $\mathrm{Wu}$ and Keysar (2007) with this online task would make it clearer that performance on this task has accurately indexed cultural differences in perspective taking ability. In conclusion, it seems that cultural variations in theory of mind concept did not have an effect on performance on the director task. This may have been because the online measure was not intuitive to Māori or Pasifika participants. Alternatively, the online measure may not have been sensitive enough to detect cultural variations in performance. It was found that all cultural groups 
made more errors when a distractor was present and thus are subject to an egocentric bias. The fact that Māori and Pasifika, who tend to be collectivist, did not outperform Pakeha in the actor director task challenges earlier assertions that collectivist cultures as a whole outperform individualists. 


\section{References}

Apperly, I. A., \& Butterfill, S. A. (2009). Do humans have two systems to track beliefs and belief-like states? Psychological Review, 116(4), 953-970. http://dx.doi.org.helicon.vuw.ac.nz/10.1037/a0016923

Apperly, I. A., Carroll, D. J., Samson, D., Humphreys, G. W., Qureshi, A., \& Moffitt, G. (2010). Why are there limits on theory of mind use? Evidence from adults' ability to follow instructions from an ignorant speaker. Quarterly Journal of Experimental Psychology, 63(6), 1201-1217.

https://doi.org/10.1080/17470210903281582

Baillargeon, R., Scott, R. M., \& He, Z. (2010). False-belief understanding in infants. Trends in Cognitive Sciences, 14(3), 110-118. https://doi.org/10.1016/j.tics.2009.12.006

Barrett, H. C., Bolyanatz, A., Crittenden, A. N., Fessler, D. M. T., Fitzpatrick, S., Gurven, M., Henrich, J., Kanovsky, M., Kushnick, G., Pisor, A., Scelza, B. A., Stich, S., von Rueden, C., Zhao, W., \& Laurence, S. (2016). Small-scale societies exhibit fundamental variation in the role of intentions in moral judgment. Proceedings of the National Academy of Sciences of the United States of America, 113(17), 4688-4693. JSTOR.

Barrett, H. C., Broesch, T., Scott, R. M., He, Z., Baillargeon, R., Wu, D., Bolz, M., Henrich, J., Setoh, P., Wang, J., \& Laurence, S. (2013). Early false-belief understanding in traditional non-Western societies. Proceedings: Biological Sciences, 280(1755), 1-6. JSTOR.

Bidois, E. (2016). Wairua, mauri, and the voice-hearing experience. Part 2. Retrieved from http://www.hearingvoices.org.nz/index. php/different-perspectives/maori-perspective/37-wairua-mauriand-thevoice-hearing-experience-article-2-by-egan-bidois

Brison, K. J. (2001a). Crafting Sociocentric Selves in Religious Discourse in Rural Fiji. Ethos, 29(4), $453-474$. JSTOR.

Brison, K. J. (2001b). Crafting sociocentric selves in religious discourse in rural Fiji. Ethos, 29(4), 453-474.

Chopik, W. J., O’Brien, E., \& Konrath, S. H. (2017). Differences in Empathic Concern and Perspective Taking Across 63 Countries. Journal of Cross-Cultural Psychology, 48(1), 23-38. https://doi.org/10.1177/0022022116673910

Clements, W. A., \& Perner, J. (1994). Implicit understanding of belief. Cognitive Development, 9(4), 377-395. https://doi.org/10.1016/0885-2014(94)90012-4

Dumontheil, I., Apperly, I. A., \& Blakemore, S.-J. (2010). Online usage of theory of mind continues to develop in late adolescence. Developmental Science, 13(2), 331-338. https://doi.org/10.1111/j.1467$\underline{7687.2009 .00888 . x}$

Dumontheil, I., Küster, O., Apperly, I. A., \& Blakemore, S.-J. (2010). Taking perspective into account in a communicative task. NeuroImage, 52(4), 1574-1583. https://doi.org/10.1016/j.neuroimage.2010.05.056

Durie, M. H. (1995). Te hoe nuku roa framework a maori identity measure. The Journal of the Polynesian Society, 104(4), 461-470.

Fagenson-Eland, E., Ensher, E. A., \& Burke, W. W. (2004). Organization Development and Change Interventions: A Seven-Nation Comparison. The Journal of Applied Behavioral Science, 40(4), 432-464. https://doi.org/10.1177/0021886304270822

Fiji's Indian Migrants: A History to the End of Indenture in 1920. (1964). International Affairs, 40(4), 765766. https://doi.org/10.1093/ia/40.4.765b

Flavell, J. H., Everett, B. A., Croft, K., \& Flavell, E. R. (1981). Young children's knowledge about visual perception: Further evidence for the Level 1-Level 2 distinction. Developmental Psychology, 17(1), 99-103. http://dx.doi.org.helicon.vuw.ac.nz/10.1037/0012-1649.17.1.99 
Gall, T. L., Malette, J., \& Guirguis-Younger, M. (2011). Spirituality and Religiousness: A Diversity of Definitions. Journal of Spirituality in Mental Health, 13(3), 158-181. https://doi.org/10.1080/19349637.2011.593404

Gervais, M. M. (2013). Structures of Sentiment: Mapping the Affective Bases of Social Relationships in Yasawa, Fiji [UCLA]. https://escholarship.org/uc/item/79d936s0

Hamilton, V. L., Sanders, J., Hosoi, Y., Ishimura, Z., Matsubara, N., Nishimura, H., Tomita, N., \& Tokoro, K. (1983). Universals in Judging Wrongdoing: Japanese and Americans Compared. American Sociological Review, 48(2), 199-211. JSTOR. https://doi.org/10.2307/2095105

Harrington, L., \& Liu, J. H. (2002). Self-Enhancement and Attitudes Toward High Achievers: A Bicultural View of the Independent and Interdependent Self. Journal of Cross-Cultural Psychology, 33(1), 37-55. https://doi.org/10.1177/0022022102033001003

Hofstede, G. (1984). Culture's Consequences: International Differences in Work-Related Values. SAGE.

Hughes, C. (2002). Understanding other minds: Perspectives from developmental cognitive neuroscience. International Journal of Language \& Communication Disorders, 37(1), 74-76.

Kelly, J. D. (1988). From Holi to Diwali in Fiji: An Essay on Ritual and History. Man, 23(1), 40-55. JSTOR. https://doi.org/10.2307/2803032

Kemmelmeier, M., Burnstein, E., Krumov, K., Genkova, P., Kanagawa, C., Hirshberg, M. S., Erb, H.-P., Wieczorkowska, G., \& Noels, K. A. (2003). Individualism, Collectivism, and Authoritarianism in Seven Societies. Journal of Cross-Cultural Psychology, 34(3), 304-322. https://doi.org/10.1177/0022022103034003005

Kennedy, V., Cram, F., Paipa, K., Pipi, K., \& Baker, M. (2015). Wairua and cultural values in evaluation. 83. https://doi.org/10.18296/em.0005

Kessler, K., Cao, L., O’Shea, K. J., \& Wang, H. (2014). A cross-culture, cross-gender comparison of perspective taking mechanisms. Proceedings: Biological Sciences, 281(1785), 1-9. JSTOR.

Kline, M. A., Boyd, R., \& Henrich, J. (2013). Teaching and the Life History of Cultural Transmission in Fijian Villages. Human Nature, 24(4), 351-374. https://doi.org/10.1007/s12110-013-9180-1

Kuhlen, A. K., \& Brennan, S. E. (2010). Anticipating Distracted Addressees: How Speakers' Expectations and Addressees' Feedback Influence Storytelling. Discourse Processes, 47(7), 567-587.

https://doi.org/10.1080/01638530903441339

Legg, E. W., Olivier, L., Samuel, S., Lurz, R., \& Clayton, N. S. (n.d.). Error rate on the director's task is influenced by the need to take another's perspective but not the type of perspective. Royal Society Open Science, 4(8), 170284. https://doi.org/10.1098/rsos.170284

Li, J., Liu, L., Chalmers, E., \& Snedeker, J. (2018). What is in a name?: The development of cross-cultural differences in referential intuitions. Cognition, 171, 108-111. https://doi.org/10.1016/j.cognition.2017.10.022

Liu, D., Wellman, H. M., Tardif, T., \& Sabbagh, M. A. (2008). Theory of mind development in Chinese children: A meta-analysis of false-belief understanding across cultures and languages. Developmental Psychology, 44(2), 523-531. https://doi.org/10.1037/0012-1649.44.2.523

Low, J. (2010). Preschoolers' Implicit and Explicit False-Belief Understanding: Relations With Complex Syntactical Mastery. Child Development, 81(2), 597-615.

Luk, K. K. S., Xiao, W. S., \& Cheung, H. (2012). Cultural effect on perspective taking in Chinese-English bilinguals. Cognition, 124(3), 350-355. https://doi.org/10.1016/j.cognition.2012.05.016

Luhrmann, T. (2011). Toward an anthropological theory of mind. Suomen Antropologi: Journal of the Finnish Anthropological Society, 36(4), 5-69. 
Ma-Kellams, C., \& Blascovich, J. (2012). Inferring the Emotions of Friends Versus Strangers: The Role of Culture and Self-Construal. Personality and Social Psychology Bulletin, 38(7), 933-945. https://doi.org/10.1177/0146167212440291

Markus, H. R., \& Kitayama, S. (1991). Culture and the self: Implications for cognition, emotion, and motivation. Psychological Review, 98(2), 224-253. http://dx.doi.org/10.1037/0033-295X.98.2.224

Marsden, M. (2003). The woven universe: selected writings of Rev. Māori Marsden. Estate of Rev. Māori Marsden.

Mavoa, H. M., Park, J., Tupounuia, P., \& Pryce, C. R. (2003). Tongan and European Children's Interactions at Home in Urban New Zealand. Ethos, 31(4), 545-576.

McNamara, R. A., \& Henrich, J. (2017). Kin and kinship psychology both influence cooperative coordination in Yasawa, Fiji. Evolution and Human Behavior, 38(2), 197-207. https://doi.org/10.1016/j.evolhumbehav.2016.09.004

McNamara, R. A., Willard, A. K., Norenzayan, A., \& Henrich, J. (2019). Weighing outcome vs. intent across societies: How cultural models of mind shape moral reasoning. Cognition, 182, 95-108.

https://doi.org/10.1016/j.cognition.2018.09.008

Miller, J. G. (1984). Culture and the development of everyday social explanation. Journal of Personality and Social Psychology, 46(5), 961-978. https://doi.org/10.1037/0022-3514.46.5.961

Ochs, E. (1982). Talking to Children in Western Samoa. Language in Society, 11(1), 77-104.

Podsiadlowski, A., \& Fox, S. (2011). Collectivist value orientations among four ethnic groups: Collectivism in the New Zealand context. New Zealand Journal of Psychology, 40(1), 5-19.

Pohatu, T. W., \& Pohatu, H. (2011). Mauri: Rethinking human wellbeing. Mai Review, 3, 1-12.

Perner, J., \& Ruffman, T. (2005). Infants’ Insight into the Mind: How Deep? Science, 308(5719), $214-216$. https://doi.org/10.1126/science.1111656

Pyers, J. E., \& Senghas, A. (2009). Language Promotes False-Belief Understanding: Evidence From Learners of a New Sign Language. Psychological Science, 20(7), 805-812. JSTOR.

Qureshi, A. W., Apperly, I. A., \& Samson, D. (2010). Executive function is necessary for perspective selection, not Level-1 visual perspective calculation: Evidence from a dual-task study of adults. Cognition, 117(2), 230-236. https://doi.org/10.1016/j.cognition.2010.08.003

Rubio-Fernández, P. (2017). The director task: A test of Theory-of-Mind use or selective attention? Psychonomic Bulletin \& Review, 24(4), 1121-1128. https://doi.org/10.3758/s13423-016-1190-7

Rubio-Fernández, P., \& Geurts, B. (2013). How to Pass the False-Belief Task Before Your Fourth Birthday. Psychological Science, 24(1), 27-33. https://doi.org/10.1177/0956797612447819

Ruffman, T., Garnham, W., Import, A., \& Connolly, D. (2001). Does Eye Gaze Indicate Implicit Knowledge of False Belief? Charting Transitions in Knowledge. Journal of Experimental Child Psychology, 80(3), 201224. https://doi.org/10.1006/jecp.2001.2633

Ruffman, T., Taumoepeau, M., \& Perkins, C. (2012). Statistical learning as a basis for social understanding in children. British Journal of Developmental Psychology, 30(1), 87-104. https://doi.org/10.1111/j.2044$\underline{835 X .2011 .02045 . \mathrm{X}}$

Rumsey, A. (2000). Agency, Personhood and the "I" of Discourse in the Pacific and Beyond. The Journal of the Royal Anthropological Institute, 6(1), 101-115. JSTOR.

Rumsey, A. (2008). Introduction: Cultural and Linguistic Anthropology and the Opacity of Other Minds. Anthropological Quarterly, 81(2), 407-420. http://dx.doi.org.helicon.vuw.ac.nz/10.1353/anq.0.0005 
Schneider, D., Nott, Z. E., \& Dux, P. E. (2014). Task instructions and implicit theory of mind. Cognition, 133(1), 43-47. https://doi.org/10.1016/j.cognition.2014.05.016

Shulruf, B., Hattie, J., \& Dixon, R. (2007). Development of a New Measurement Tool for Individualism and Collectivism. Journal of Psychoeducational Assessment, 25(4), 385-401.

https://doi.org/10.1177/0734282906298992

Schluter, P. J., Tautolo, E.-S., \& Paterson, J. (2011). Acculturation of Pacific mothers in New Zealand over time: Findings from the Pacific Islands Families study. BMC Public Health, 11(1), 307.

https://doi.org/10.1186/1471-2458-11-307

Southgate, V., Senju, A., \& Csibra, G. (2007). Action Anticipation through Attribution of False Belief by 2Year-Olds. Psychological Science, 18(7), 587-592.

Surian, L., Caldi, S., \& Sperber, D. (2007). Attribution of Beliefs by 13-Month-Old Infants. Psychological Science, 18(7), 580-586.

Tamasese, K., Peteru, C., Waldegrave, C., \& Bush, A. (2005). Ole Taeao Afua, the new morning: A qualitative investigation into Samoan perspectives on mental health and culturally appropriate services. Australian \& New Zealand Journal of Psychiatry, 39(4), 300-309.

Tevita, O. (2005). Tauhi va: Nurturing Tongan sociospatial ties in Maui and beyond. The Contemporary Pacific, $17(1), 83-114$.

Throop, C. J. (2012). On the Varieties of Empathic Experience: Tactility, Mental Opacity, and Pain in Yap. Medical Anthropology Quarterly, 26(3), 408-430. https://doi.org/10.1111/j.1548-1387.2012.01225.x

Träuble, B., Marinović, V., \& Pauen, S. (2010). Early Theory of Mind Competencies: Do Infants Understand Others' Beliefs? Infancy, 15(4), 434-444. https://doi.org/10.1111/j.1532-7078.2009.00025.x

Trnka, S. (2012). Cleanliness in a Caste-less Context: Collective Negotiations of Purity and Pollution among Indo-Fijian Hindus. Anthropological Forum, 22(1), 25-43. https://doi.org/10.1080/00664677.2012.652586

Valentine, H., \& Tassell, N. (n.d.). He aha te wairua? He aha te mauri? 35.

Valentine, H., Tassell-Mataamua, N., \& Flett, R. (2017). Whakairia ki runga: The many dimensions of wairua. $46(3), 8$.

Vorauer, J. D., \& Cameron, J. J. (2002). So close, and yet so far: Does collectivism foster transparency overestimation? Journal of Personality and Social Psychology, 83(6), 1344-1352. http://dx.doi.org/10.1037/00223514.83.6.1344

Wellman, H. M., Cross, D., \& Watson, J. (2001). Meta-Analysis of Theory-of-Mind Development: The Truth about False Belief. Child Development, 72(3), 655-684. https://doi.org/10.1111/1467-8624.00304

Willard, A. K. (2018). Religion and prosocial behavior among the Indo-Fijians. Religion, Brain \& Behavior, 8(2), 227-242. https://doi.org/10.1080/2153599X.2016.1267032

Wilson, J. (1975). Text and context in Fijian Hinduism: Uses of religion. Religion, 5(1), 53-68. https://doi.org/10.1016/0048-721X(75)90029-9

Wong, V. C., \& Wyer, R. S. (2016). Mental traveling along psychological distances: The effects of cultural syndromes, perspective flexibility, and construal level. Journal of Personality and Social Psychology, 111(1), 17-33. http://dx.doi.org/10.1037/pspa0000048

Wu, S., \& Keysar, B. (2007). The Effect of Culture on Perspective Taking. Psychological Science, 18(7), 600606. 
Appendix

OSF Page: https://osf.io/s93zv/ 